\title{
Experiences of sustainability assessment: an awkward
}

\author{
adolescence
}

Bob Frame*, Jo Cavanagh

Manaaki Whenua - Landcare Research, Private Bag 40, Lincoln 7640, New Zealand

\begin{abstract}
Accounting for sustainability is approaching its (metaphoric) teenage years keen to assert independence, yet still reliant on the security of its background disciplines and not quite mature enough to make its own judgements. One example is the Sustainability Assessment Model, a full-cost-accounting tool that monetizes externalities. This paper examines its application in case studies where it faced issues over assessment boundaries, data limitations, and stakeholder engagement. There is much development needed, especially around engagement and externalities, before such techniques can achieve independent lives of their own away from their research-based caregivers.
\end{abstract}

* Corresponding author: Tel.: +64 3321 9673; fax: +64 33219996.

E-mail addresses: frameb@landcareresearch.co.nz (B. Frame), cavanaghj@landcareresearch.co.nz (J. Cavanagh). 
Keywords: Clumsy solution; Externalities; Full-cost accounting; New Zealand; Postnormal sustainability technologies; Wicked problems

\section{Introduction}

This paper positions itself in the burgeoning literature of accounting as a technology for sustainability and, as such, follows extensive reviews of, mostly, theory and, to a much lesser extent, practice (e.g. Astleithner \& Hamedinger, 2003; Birkin, 2000; Birkin, Edwards, \& Woodward, 2005; Boyce 2000, Brown, 2007; Dalal-Clayton \& Sadler, 2005; Lamberton, 2005; Ness et al., 2007; O'Connor, 2006; Unerman, Bebbington, \& O’Dwyer, 2007; van Asselt \& Rijkens-Klomp, 2002; Weaver \& Rotmans, 2006;). Such technologies can be seen as part of a wider set as society grapples with the challenges of global environmental and social change that sweep from climate change to resource depletion and effects of globalization. So extensive is this literature that the cohort of new subjects is clearly no longer in its (metaphoric) infancy. So colossal are the challenges it addresses that it would also be foolhardy to suggest that mature solutions are in place to redress the situation. Indeed it is, alas, difficult to cite many examples of runaway successes in practice and so a reflexive approach to all such examples is crucial if the transformation of the accounting discipline is to take place (Bang, 2004; Birkin, 2000; Birkin et al., 2005).

It is in this vein that we examine the needs as portrayed in the global literature for these technologies (Section 2). We then look at the extent to which these technologies have been addressed by one particular tool used to look at infrastructure 
projects in a separate jurisdiction (New Zealand) from that of its 'birth' (UK) (Section 3). While found to have fallen short of the ideal, the process is subjected to what is intended as good parenting through identifying its key characteristics and connecting the extent to which they have been achieved (Section 4). In particular we look at the involvement of stakeholders in the deliberation and the availability of acceptable data. However, as with so many adolescents, we conclude that the end result is distant and the maturation process far from certain or predictable (Section 5).

\section{Sustainability assessment as a post-normal sustainability technology}

\subsection{Post-normal sustainability technologies}

The vast array of techniques and practices aimed at promoting sustainability can be reconceptualized through a post-normal science lens based on the approaches developed by Jerry Ravetz and Silvio Funtowicz in the mid-1980s to mid-1990s (notably Funtowicz \& Ravetz, 1993, 1994; Ravetz, 1987) and in subsequent literature (Funtowicz 2006; Ravetz, 2006; Ravetz \& Funtowicz, 1999). From this has arisen the concept of post-normal sustainability technologies (PNSTs), which are emerging as contributions to tackling the highly complex, uncertain, value-laden issues facing a resource-constrained world (Frame \& Brown, 2008; Haag \& Kaupenjohann, 2001; Mayumi \& Giampietro, 2006). In keeping with the newness of the approach, the topic is 
adopting and accumulating its own terminology, which, although appearing adolescent, actually has an older pedigree (Frame, in press; Frame \& Brown, 2008). There is a clear pertinence to contemporary 'wicked problems' (Rittel \& Webber, 1973) which have been reclassified by Rayner (2006) to be:

- Symptomatic of deeper problems

- Unique opportunities that cannot be easily reversed

- Unable to offer a clear set of alternative solutions

- Characterized by contradictory certitudes

- Contain redistributive implications for entrenched interests, and

- Persistent and insoluble

'Clumsy solutions' were originally defined by Shapiro (1988) and, again, more recently as where "all the 'voices' (are) heard and responded to by the others" (Verweij et al., 2006, p. 822) and also in Verweij \& Thompson (2006) and Rayner (2006).

Stakeholder engagement in sustainability issues is critical for the legitimacy and quality of decisions and the admission of complexity and value-laden judgements in decision-making and accountability processes. Stakeholders will need new forms of expertise in their interactions with more traditional forms of expertise in order to coproduce knowledge about sustainability. Ideological pluralism and value diversity is also central to the sustainability agenda and with PNSTs; the values-based nature of the issues involved is articulated in a way that seeks to engage with the political. Frame and 
Brown (2008) identified processes essential to the practice of PNSTs that include extended peer communities and multi-actor heuristics (as originally proposed by Funtowicz and Ravetz), and agonistic processes (Bebbington et al., 2007; Brown, 2007; Mouffe, 2000, 2005).

We seek here to examine one possible PNST - a particular variant of full-cost accounting (FCA) (see reviews by Antheaume (2007), Bebbington (2007), and Herbohn (2005)). Our intent is to understand better its development and to inform how its use may be improved upon. These accounting technologies have been theorized by Birkin (2000), Birkin et al. (2005), and Lamberton (2005), among others. The latter's frameworks are used to assess the usefulness of the tool when actually used. Before doing so we examine the overall discourse on externalities in FCA, as FCA generates information about externalities that are not currently reflected in the open market and which are not likely to be reflected in the market in the near future. Thus, the costs generated by FCA are not 'real' in the sense that they will be borne by the project's owners. Rather, the costs are notional and provide a glimpse of the total costs and benefits to society of an activity within the defined boundary. The primary benefit of FCA is the information on externalities that it generates, which was previously unavailable to decision makers. It is to this that we now turn.

\subsection{Externalities}


Of particular interest to the development of an accounting PNST, FCA is the treatment of the concept of externalities or, more specifically in accounting terms, external costs. Monetization of externalities is a difficult and contentious element of FCA, especially as the problems which sustainable development seeks to address arise from fundamental structural weaknesses within society and are not amenable to attempts that reduce, for example, 'the environment' to a monetary figure. An externality "arises when the social, environmental or economic activities of one group of persons have an impact on another group and when that impact is not fully accounted or compensated for, by the first group" (http://www.externe.info/). This is a fundamental component of any provision of a technology that will tackle long-term sustainability as it is essential to account for the depletion or creation of all forms of capital. Although the origins of externalities are in welfare economics (Pigou, 1920), the topic has, over time, developed momentum including major contributions tending towards sustainability-related issues in more recent years (key works include Arrow, 1963; Coase, 1960; Hohmeyer, 1988; Pearce 1978; Polanyi, 1944; Sagoff, 1988; Sen, 1977). More recently there has been increasing transdisciplinary interest in externalities, from mostly European researchers, in journals such as Ecological Economics and Energy Policy with leading pieces by Kim (2007), Krewitt (2002), Markandya \& Tamborra (2002), Söderholm \& Sundqvist (2003), and Stirling (1997), and, in addition to energy, in sectors such as agriculture in the UK (Pretty et al., 2000), and transport (Friedrich \& Bickel, 2001).

More influential on the uptake of externalities in the policy environment was the European Commission's 'ExternE' (External costs of Energy) European Research Network project launched in collaboration with the US Department of Energy in 1991 6 
and running until 2006. It was a comprehensive attempt ${ }^{\mathrm{a}}$ to provide an operational accounting framework for the assessment of external costs of energy technologies. It adopted a consistent 'bottom-up' methodology to evaluate the external costs associated with a range of different fuel cycles and, in latter years, transport-related externalities. This internalization of external costs was intended as a European Union strategy ${ }^{\mathrm{b}}$ to rebalance the social and environmental dimension with the purely economic one, accordingly leading to greater environmental sustainability. To support this internalization, socio-environmental damages were first estimated then monetized. The project produced considerable material on methods and data (e.g. European Commission, 1995, 2005). In his review of ExternE, Krewitt (2002, p. 840) notes "the ExternE label became a 'recognized' brand, the scientific quality of the work was well accepted on the international level. National and international organizations got used to ExternE numbers as a standard source for external cost data”. However, although applauding ExternE's “large achievements”, Krewitt does express concerns that "ExternE somehow failed to come up with a set of comprehensive and precise external cost data that are sufficiently robust or satisfying the original purpose" $(2002$, p. 846). While praising the process by which greater understanding of environmental impacts

${ }^{a}$ From 1991 to 2005, the ExternE project involved more than 50 research teams in over 20 countries and ExternE Phase III was valued around 5 MECU (http://externe.jrc.es/). Full details are available at: http://www.externe.info/.

\footnotetext{
${ }^{\mathrm{b}}$ For example as expressed in the Fifth Framework Programme of the European Commission and in the Göteborg Protocol of 2001.
} 
were achieved he also cautions that "many people have the expectation that external costs are as simple to understand as price tags in a store" (2002, p. 847).

In a further examination of ExternE, Söderholm and Sundqvist (2003, p. 333) reach similar conclusions that are particularly relevant and so are reproduced in full: "Environmental valuation based on welfare economic theory builds on restrictive behavioral foundations and can only partly model moral values, although such values are an essential part of people's preference towards the environment. In addition, public preferences are seldom exogenously given as is commonly assumed in economic theory, but are instead formed in public discourse. For this reason, the range of electricity externalities where economic valuation (and thus cost-benefit analysis) should be applied is likely to be narrower than often assumed"...[and] ...the paper concludes that many power generation externalities are either inherently "new" or inherently "complex". In these cases, the initial challenge lies not in "discovering" private preferences, but in specifying the conditions for public discourse over common ways of understanding what the pertinent issues are about. This implies that research on the environmental externalities of power generation must, in addition to refining the theory and the applications of existing non-market valuation techniques, also address the instruments and content of political and moral debate.

$\operatorname{Kim}(2007$, p. 421), in his review of externalities, takes a wider orbit and identifies two approaches: the neoclassical (such as that used in ExternE) and the institutional (using social cost valuation and multicriteria decision-making methods). He concludes: “...considering all the achievements and weakness of the neoclassical and institutional approaches, the combination of monetary measurement with holistic and 8 
qualitative evaluation can be suggested as an important research priority. The qualitative and organic aspects of economic systems tend to be ignored in the neoclassical economics because of its consequential focus and welfarism. The institutional approach needs some objective measure which is not based on the individual preference".

In the accounting literature, recent interest on externalities (e.g. Antheaume 2007; Bebbington 2007; Bebbington et al. 2001, 2007; Bebbington, Brown, \& Frame 2007; Herbohn 2005) highlights a need for more critical reflection on the use of externalities. It is against this background that we now focus on uses of the Sustainability Assessment Model (SAM), a full-cost-accounting tool.

\subsection{Sustainability Assessment Model as a PNST}

SAM was developed in the UK by BP and by Genesis Oil and Gas Consultants (UK division) with Jan Bebbington (Baxter, Bebbington, \& Cutteridge, 2004; Bebbington et al. 2001; Bebbington \& McGregor 2005, Bebbington 2007) using a fullcost-accounting (FCA) approach to assess a discrete project (where a 'project' consists of any economic activity for which a scope can be defined and acceptable boundaries laid). It arose from a perceived need within BP to understand more fully the concepts of sustainability and what forms of institutional re-engineering might be possible to enable the oil and gas sector to work in a more sustainable manner. In order to do this effectively it was judged necessary to have a tool that operated in the currency of major investment decisions at a governance level, namely money; hence the drive for fully 
costed estimates of the externalities. The first SAM was developed around the decisionmaking process for a specific oil and gas field development with a view to SAM becoming part of the overall decision-making processes within BP (Baxter et al., 2004).

SAM considers the project over its full life-cycle and identifies and monetizes the project's impacts, including externalities, through dialogue with stakeholders. Specifically, SAM is designed to include monetization of the costs of externalities arising from social, environmental, resource and economic impacts. The main approaches to monetization, such as the maintenance-cost approach and a variety of approaches under the broad heading of the damage-cost approach (see Bebbington et al., 2001, pp. 63-67), may yield significantly different measures of externalities. As a result, knowing what the resulting figures mean is often very difficult. In the case of SAM damage-cost estimates are used (in the main) to monetize externalities. While there can be significant opposition to the monetization of externalities (e.g. as noted by Lamberton, 2005), SAM's intent is to facilitate the consideration of sustainability issues in arenas where economic rationalism dominates management decisions, and make the subjectivity and assumptions associated with monetization explicit (Bebbington, Brown, \& Frame, 2007).

We now look at the provenance of SAM and its transition to a new jurisdiction to see if the impetus with which it was initially developed transfers to a new domain. In New Zealand, SAM has been used to look essentially at infrastructure projects (in the broadest sense) in a process that started in 2001 with initial interest expressed by a broad range of stakeholders (Bebbington \& Frame, 2003; Bebbington 2007; Cavanagh 2005, 2007; Cavanagh, Frame, \& Lennox, 2006). These case studies in sustainability 
assessment need to be seen in the overall discourse of sustainable development and infrastructure in New Zealand as reviewed by Chapman et al. (2003), which expressed particular interest in externalities and their importance. However, the subsequent government 'Sustainable Development Programme of Action' did not include assessment of externalities as one of its ten guiding principles (Department of Prime Minister and Cabinet, 2003). Though specific guidelines were not established for the use of sustainability assessment tools, there was specific reference to decoupling of economic growth from environmental impact (Principle 7) though as was highlighted in the review of the programme this was not given a particularly high profile (Frame $\&$ Marquardt, 2006). It is also noteworthy that although there has been considerable renewed interest by central and local government in sustainability, this has (at the time of writing) yet to include much on the assessment of externalities.

While the UK SAM was developed by a team comprising academic researchers and industry-based consultants devoting considerable time to devising a solution to a common problem, the New Zealand version was developed as part of a governmentsupported research project ${ }^{\mathrm{c}}$. Specifically it was intended to provide: "assessment mechanisms that address the integration of various sustainable development dimensions to provide public and private sector decision- and policy-makers with tools to understand the impacts of different development pathways on all dimensions of

\footnotetext{
${ }^{\mathrm{c}}$ SAM was developed under New Zealand Foundation for Research, Science and Technology (FRST) funding for the 'Building capacity for sustainable development: The enabling research' project (C09X0310) and the following quote is an extract from one of the project objectives.
} 
sustainable development; and document success stories in achieving 'win-wins' rather than trade-offs between two or more dimensions of sustainability" (FRST contract). This was congruent with perceived needs at the design stage of the project that New Zealand businesses and public sector organizations regarded SAM as able to assist in developing more sustainable ways of operating (Bebbington \& Frame, 2003).We will now examine SAM's application in urban case studies in New Zealand and our interest is in the use of SAM to develop meaningful dialogue processes about externalities.

\section{SAM in New Zealand}

\subsection{Context}

Our initial intent was to examine the assemblage of factors that would enable SAM, as an example of a PNST, to flourish and to then identify key factors and barriers to successful implementation. As various case studies developed, it became clear that, in the use of SAM, the process of engagement with the various stakeholders was critical to its success. Recent New Zealand case studies are now used to illustrate the application of SAM in New Zealand, before we discuss experiences gained.

SAM follows an FCA approach to assess a project over its life cycle by identifying and monetizing the project's impacts, including externalities. Impacts are identified and categorized in fields typically grouped under four headings: economic, 
resource use, environmental and social impacts. The economic category is the economic benefit that accrues from the project and notionally represents the money going into society, or the project's contribution to GDP. The resource category includes the cost of using finite supplies of raw materials and land for the given project. The environmental category includes the cost of environmental damage such as emissions into the atmosphere and impacts of wastes generated by the project. It may also include benefits such as improved biodiversity or improvements in environmental quality. The social category captures the potential social benefits arising from the project such as improved quality of life. Potential social costs associated with the project, such as road accidents and workplace injuries, are also captured.

When presented visually, these categories provide a 'sustainability profile' for a given project that can be used to compare and communicate the relative sustainability of different options. However, it should be noted that it is not known what a truly sustainable project would look like; thus the 'sustainability profile' developed through the SAM process more accurately provides a picture of the relative unsustainability of the given project.

\subsection{Case studies}

Two examples of the implementation of SAM in New Zealand through various infrastructure programmes are now detailed. Other case studies, including organic recycling (Cavanagh et al., 2006), as well as a public library complex, a green-field 
housing development and transport studies were also conducted and the analysis of them is consistent with the two discussed in this paper.

\subsubsection{Waste management}

In this case study different waste-diversion programmes (community-based resource recovery operations, and commercial-scale resource recovery operations) were compared with disposal to landfill (Cavanagh, 2005). This project was undertaken for a regional authority specifically to initiate conversations around non-economic benefits of various waste management options. Interviews were held with representatives from a range of waste disposal and diversion operations to collect operational data relevant to the SAM assessment, and to ascertain what 'impacts' were considered relevant for sustainability considerations by the different operators.

Operational data provided the magnitude of impacts relevant to the assessment after conversion into units relevant for quantifying externalities, e.g. emissions associated with transport of waste or recyclables, or machinery operation. This was primarily undertaken using WISARD Lifecycle Software for Waste Management in New Zealand (see section 4.1.2). For confidentiality and to provide an appropriate comparison between operations, assessments were based on generic scenarios to reflect 'typical' activities undertaken for different operations. Valuation of externalities was undertaken where possible using credible sources such as national damage-cost estimates for key air pollutants (Booz, Allen and Hamilton, 2005) (see section 4.1.2). Proxy valuations were used to include items relevant to sustainability but not easily 
monetized. Specifically, the social benefit of education in waste minimization and resource recovery was valued by assuming that additional waste was diverted from landfill through either increased recycling or avoided waste generation as a result of social marketing.

Initial SAM signatures were presented to a working group of representatives from the contracting council and a representative from central government. This enabled identification of any additional impacts, discussion on proxy valuations and on research constraints; particularly those around the analyses' boundaries. For example, waste collection and waste management on-site were considered separately to provide the focus on the differences between the waste management activities, as opposed to the impacts of transportation associated with waste management. Further, the wider benefits and costs associated with resource recovery (e.g. offsetting the use of raw materials, offsetting the production of new products, energy used for remanufacturing of recovered materials) were unable to be included in the analysis. Inclusion of these items would provide a better picture of relative sustainability of different options, and is potentially important in enabling decisions to be made that actually enhance the sustainability of waste management (including the impact of reduced consumption).

Analysis revealed that resource and environmental costs were unexpectedly small compared with economic impacts for all scenarios although greatest for landfill operations. Resource costs were primarily associated with fuel and infrastructure. Environmental costs arose mainly from impact of air emissions and, for landfill operations, expenditure to mitigate environmental effects. The apparently negligible resource and environmental benefit of diversion activities may arise from the exclusion 
of certain activities from those scenarios. However, it may also reflect an undervaluation of these impacts.

Operational costs and the benefits of employment dominated all signatures. The social benefit generated by waste diversion activities, in particular community-based operations, was the key difference between waste disposal and diversion scenarios; small-scale community-based operations deliver the greatest social benefit per dollar spent. These social benefits arose from the greater range of activities (e.g. waste education and awareness programmes, waste exchange) and greater focus on employing long-term unemployed or, in this specific case, intellectually challenged people undertaken by community-based operations compared with commercial waste-diversion operations. Thus the analysis was useful in highlighting these benefits from the community-based operations.

In summary, this case study provided the regional authority with a useful conversation starter around the non-economic benefits of alternatives for waste management and went on to generate interest from a wider range of potential stakeholders.

\subsubsection{Housing}

The two housing projects were different in scale and for different stakeholders: one is the redevelopment of four conjoined units used for social housing - case study (a) (Cavanagh, 2007); while the other is the redevelopment of a small number of houses also used as social housing - case study (b). 
In both cases the extent of stakeholder engagement was primarily limited to the contracting organization. In case study (a) there was good engagement with representatives from different parts of the organization who participated in meetings to discuss the potential impacts of the project. The organization also made all relevant data available, and provided contacts for relevant social agencies. This engagement was largely driven by a key individual within that organization who considered that it was important and necessary for the wider (environmental, resource, social) impacts of a specific housing project to be considered alongside the economic aspects. SAM was viewed as a potential mechanism to achieve this. In contrast, case study (b) involved a larger number of stakeholders from different organizations but lacked the same degree of engagement in considering non-economic impacts.

Case study (a) compared the retention of four conjoined two-bedroom units constructed in the early 1950 s with replacement by six pensioner units. Data on construction materials and operational data on the houses were gathered from the organization, while literature searches were undertaken to identify links of various aspects of housing with social impacts. The resources used and air emissions associated with the production of construction materials were based on Australian life-cycle inventory data provided in LISA (Life-cycle analysis In Sustainable Architecture, http://www.lisa.au.com), along with estimates of health impacts of housing insulation (Howden-Chapman et al., 2007). Economic impacts dominated the profile, while all other 'external' impacts were minimal. Further, there was little difference between retaining the existing units and replacing them with the pensioner units - despite the fact the new units were intended to be more energy and water efficient, and there was greater housing density. 
To investigate whether the externalities of the resource, environmental and social attributes of the housing developments could be included in the existing financial model typically used for decision making in this organization, an alternative assessment approach was also used for this study. In this case the valuations developed in the SAM process were included as additional elements in the model. This model generated an internal rate of return (IRR) over a 15-year period, and included various financial assumptions. Including the environmental, resource and social valuations changed the estimated IRR from 7.66 to 5.57 for the old units and from 7.56 to 7.06 for the pensioner units. The decrease in IRR was largely driven by the estimated operational resource use impacts (electricity, water). The higher IRR (after inclusion of the externalities) for the pensioner units compared with the conjoined units reflects the lower resource use and health benefits (as a result of having a warmer, drier house) of the new units. Thus, while the SAM signature was less useful in discriminating between options, inclusion of the SAM information in the existing financial model allowed greater discrimination between the two options, and also provided information in a format familiar to organization members. This latter option is being further pursued by the organization as a means to include externalities in asset management.

As with the waste management project, resource and environmental impacts were smaller than anticipated and possibly influenced by an incomplete dataset, as well as undervaluation (see section 4.1.2). In addition, inclusion of social impacts in the assessment is limited by the availability of appropriate metrics.

For case study (b) resource costs dominated the profile, while economic and social impacts were of a similar magnitude. In this case, market rent was used to 
provide the economic impacts while resource costs were estimated as the opportunity costs of the building materials. This contrasts with our other studies, which tended to use a resource rent approach where possible, and reflects the difference obtained by the use of different valuation metrics. The social benefits were identified as being significant, although only nominal estimates of their value could be made due to an absence of data. Largely in recognition of the nominal valuation of social benefits, a multicriteria approach to the assessment of the development was also pursued to ascertain whether this elucidated more effectively which aspects of the development contributed most to sustainability. While stakeholders participated in both assessments, there was a lack of interest in the further inclusion of sustainability assessment in the assessment of the housing development. For discussion of the 'organizational' issues that contributed to this lack of uptake, see Fraser (2007).

\subsection{Observations}

The lower resource and environmental impacts compared to economic benefits in most studies was unexpected. While this could be partially attributed to the boundaries established and subsequent exclusion of certain activities, data limitations are considered a significant factor. The expectation was that sufficient data would exist to estimate physical impacts and appropriate valuations. Where limited monetization data existed, it was expected to be feasible to generate consensus costings for given impacts. However, data were disappointingly sparse. Data on environmental and 
resource use impacts were relatively easier to obtain than data on social impacts. For example, the WISARD Lifecycle Software for Waste Management in New Zealand and the Australian life-cycle inventory data provided in LISA were used to estimate resources used and environmental impacts of waste management and the production of construction materials respectively. While these data sources provided a significant amount of data, they were nonetheless incomplete for the purposes of our studies. Data to enable quantification of social impacts were scarce with only one study on quantification of one social impact (Howden-Chapman et al., 2007). Valuation of external impacts was also challenging with no institutional equivalents of ExternE or other repositories of external cost data. Where possible valuation data were drawn from credible sources: national studies on damage-cost estimates for key air pollutants (Booz, Allen and Hamilton, 2005), road transportation costs (Land Transport New Zealand, 2005) or data from Statistics New Zealand (e.g. average wage data, input-output data for employment multipliers) were used to provide valuations. Booz, Allen and Hamilton (2005) used the valuation approach of Watkiss (2002), which was based on generalized damage-cost functions developed during the ExternE process in Europe. However, such data were limited and valuation data were drawn from a variety of, primarily grey, literature (e.g. Chapman et al., 2006; Chapman, Howden-Chapman, \& O’Dea, 2004; White, Sharp, \& Reeves, 2004), and for resource impacts, valuations more appropriately reflected the opportunity costs. It was not anticipated that New Zealand specific data limitations would be a significant issue as proxies from other sources or consensus or surrogate costings could be used to indicate the relative magnitude of a particular impact. While proxy valuations were used in the waste management case study (to estimate the benefits of education on waste minimization), there was general 
expectation by stakeholders that existing research could provide robust costings for all identified impacts. Ultimately, these data limitations were significant in limiting the wider acceptance of the assessments and, importantly, in facilitating further discussion on options for improving project sustainability.

We consider that engagement with a broad range of stakeholders is important to capture all possible impacts, and to facilitate an understanding of the factors influencing sustainability. Further, this engagement allows the stakeholders to share their knowledge of the project and its outcomes, including aspects considered important from a sustainability perspective. In turn this promotes acceptance of the final assessment. The engagement process should occur throughout the assessment to generate new understanding and data. However, in our experience the process stopped at the presentation of the initial assessment, and no further discussion occurred on options for improving project sustainability.

\section{Reflections on full-cost accounting}

We now examine how effective SAM has been in contributing to sustainability accounting, using Lamberton's framework and how, in turn, this has demonstrated (or not) the qualities of a PNST.

\subsection{Contributions to sustainability accounting}


First we seek to assess if acceptance of SAM is being driven by the urgency of sustainability issues and not just motivated by technical interests. To do this with some sense of objectivity we take the various challenges encountered while undertaking the SAM assessments and discuss these using Lamberton's (2005) framework. This consists of five components as shown in Fig. 1 and which was developed as a financial accounting model to provide structure to sustainability accounting that has hitherto developed in a rather ad hoc manner. The five components are (Lamberton, 2005, p. 16):

- Objectives of the sustainability accounting framework

- Principles which underpin application of the framework

- Data capture tools, accounting records, and measurement techniques

- Reports used to present information to stakeholders

- Qualitative attributes of information reported using the framework

It is tempting to focus the discussion on comparisons of various weightings and monetization techniques used in the various interpretations of SAM used in step 2. However, our observations are that it is the process of SAM that provides the most useful insights to the relative sustainability of an activity. Specifically, the process should facilitate recognition of the type and breadth of impacts potentially arising from an activity, which mostly surpass the extent to which robust technical data is available. 
As a result we only consider the data capture (Step 3) and qualitative attributes (Step 5) in the present study.

[Fig. 1]

\subsubsection{Data capture and measurement technologies}

Establishing the limits of a SAM assessment is a critical early step that is key to the overall success of and acceptance of SAM; that is to say, an understanding of what SAM means, the wider impacts of projects, and potential influence of 'unconsidered' impacts. In particular, this includes both establishing the most appropriate time frame for analysis (how long from cradle to grave?) and identifying likely impacts. In the waste project the lifetime was taken as 35 years - the duration of resource consents in New Zealand. For the housing development, 90 years (with major refurbishment at 45 years) was used as the lifetime considered by asset managers. In both cases, the actual lifetime of the given project may extend past these estimates. The lifetime length impacts most significantly on the relative impacts associated with the initial 'start-up' (e.g. construction) as these are amortized (currently assuming $0 \%$ discount; Bebbington, Brown \& Frame, 2007) over the project lifetime. Thus, the longer the lifetime of the project, the less significant the 'start-up' impacts may be relative to those arising from operational activities.

Impacts included may be constrained by what is appropriate for comparison between options or data limitations. For example, in the waste management project, it was not possible to include the wider impacts of resource recovery (e.g. reduced 
consumption of new materials, reduced manufacture of products) and the collection of waste and recovered materials was considered separately to focus on key activities (disposal to landfill vs. resource recovery). Further, while organizations hold detailed information on operational aspects, some data pertinent to quantifying the impacts (e.g. amounts of raw materials used, environmental impacts) have to be sought from the available literature, and even then, these do not provide all the data required in developing a detailed assessment. Confidentiality requirements may also impact data gathering and utilization, while data from different sources (e.g. financial accounts from different organizations) may be provided in different ways (e.g. itemized differently) making consistent treatment of data difficult. All of this underlines that accounting can potentially be very supportive of the sustainability agenda but does not always have existing practices to support this. This suggests that much deeper institutional reform is required.

Monetization of impacts is the most contentious issue in the SAM process for the New Zealand case studies. Where possible, as noted in section 3.3, credible sources were used to provide valuations. However, such data were limited and valuation data were drawn from a variety of, primarily grey, literature (e.g. Chapman et al., 2004, 2006; White et al., 2004), and for resource impacts, valuations more appropriately reflected the opportunity costs. In some cases where data were not available surrogate measures were developed with the participation of stakeholders, although more often there was an expectation by stakeholders that research should easily provide appropriate valuations. While sensitivity testing could be used to assess the influence of significantly different valuations on the SAM profile and assist in establishing the most significant variables, altering the valuations for 'contentious' elements, namely 24 
environmental or resource impacts, often made little difference. For example, for the organic waste assessment and the waste assessments, increasing damage-cost estimates of air emissions by several orders of magnitude made minimal difference to the signatures. Ultimately, the lack of robust data, both for quantifying and monetizing impacts, was a significant limitation to the SAM process. Specifically, it closed down, as opposed to opened up, conversations on the aspects that contributed to the sustainability of a given project or how greater sustainability could be achieved.

Consideration of the social impacts raised additional issues, particularly for the housing case studies. One key issue was establishing appropriate elements that addressed the social benefits. For example, 'happier, healthier communities' that have less crime are typically features that are aspired to for sustainable housing developments. This raised two issues: one is determination of what metrics can be used to provide a measure that can be appropriately quantified and monetized; the other is the use of relativity (happier, healthier, reduced crime) in the expression of these aspirations; this implies the difference relative to a conventional housing state. In terms of the first point while some potential measures (e.g. GP visits as an indicator of health, crime rates) were generally accepted by stakeholders, other potential measures, for example suicide rates, were not accepted - despite the fact that suicide is an accepted measure of mental health and emotional well-being in national studies. In some cases, these measures may also face scale issues; depending on the scale of the development there may be negligible difference between a 'sustainable' and conventional development. The second issue - the use of relativity to express sustainability aspirations - provided a perception issue. Specifically, the use of absolute values for potential measures such as GP visits, crime impacts etc. gives rise to a negative social 25 
impact - for a sustainable development this impact is less negative than a conventional development. While this approach was the same for assessing resource and environmental impacts, stakeholders' expectations were that the social impacts of a sustainable development would always be positive and the SAM results were viewed sceptically otherwise.

\subsubsection{Qualitative attributes of sustainability accounting information}

Lamberton offers many attributes to consider in this final step but we will only take one - the irksome issue of the valuation of externalities and, in particular, their monetization. O'Connor $(2000,2006)$ has developed the concept of the Monetization Frontier and the conditions under which it can be used. This has been further extended by Frame and O'Connor (2008) to serve as a boundary over which the use of accurate valuation is no longer valid; or at least highly inaccurate. However, valorizations of a parameter can be useful if it is making a critical contribution to a discussion. In this sense it should be seen as having a 'narrative' value rather than an empirical one. This takes us into a new realm of considering the epistemological value of indicators especially when considering the complexity of sustainability issues (Miller, 2005).

We conclude that Lamberton's framework provides an elegant test of the usefulness of an accounting tool. The framework enables the tool's functionality to be unpacked and set aside from its implementation. What this discloses for SAM is a highly problematic issue around externalities. In turn this appears to be more of an issue of the sustainability discourse in the jurisdiction rather than an integral problem with the 
tool. To examine that issue it is necessary to look in more detail at the use of SAM as a PNST and also the success of a tool one step removed from those who had developed it.

\subsection{SAM's contribution as a post-normal sustainability technology}

In their development of PNSTs, Frame and Brown (2008) identify three core qualities for PNSTs which need to be present for a technology to be successful. Here we discuss only two of them, as the topic of ecological citizenship is much less relevant for the SAM case studies.

\subsubsection{Extended peer communities}

In this, evidence should be apparent for the development of communities of practice around the kinds of accounting processes that Birkin (2000) describes as demonstrating an ontology of interconnected events. Stakeholders had varying perceptions on the usefulness of SAM. In one case SAM was viewed favourably as a means to 'extend' the existing financial model upon which decisions are currently based, to include social and environmental aspects. In another, the attractiveness of the SAM assessments was the perceived potential application for benchmarking. However this application implies that all elements contributing to sustainability can be known upfront and can be defined with reasonable certainty, which is currently not the case. 
Varying levels of participation were achieved with different stakeholders. Some were "only interested if it gives us the answer we want". This runs counter to the intention of SAM to generate dialogue around options for achieving sustainability. Even with stakeholders who were more willing and eager to engage in the process, only a limited number of potential stakeholders (primarily local council or housing development staff) were involved in the initial SAM assessment. The researcher/consultant was often viewed as holder of the 'correct' answer when providing SAM assessments. This highlighted a need to change the researcherstakeholder relationship from a consultancy-type agreement to one based much more around partnership and co-evolution of results rather than contractual arrangements. This is, we propose, indicative of a 'clumsy solution' and should be embraced rather than shunned by both researcher and end-user beneficiary. It does, however, imply a significant culture change in the implementation of both research and consultancy around sustainability issues. This is unlikely to be swift or simple and the development of communities of practice around this will need to be carefully encouraged. It is also worth noting that this is not a contractual obligation but more to do with a sense of duty or responsibility and, as such, complies with Hyde's distinction: "It is the cardinal difference between gift and commodity exchange that a gift establishes a feeling-bond between two people, while the sale of a commodity leaves no necessary connection" (1983, p. 56).

It requires of its participants an ability to move beyond a contractual relationship to a partnership approach wherein individuals and entities are required to take up their responsibilities and duties to society in addition to their rights to shareholders to maximize the use of economic capital. It requires increasing emphasis on aspects of 28 
trust. In so doing there is a distinct shift in the locus of authority. This is in keeping with notions that the ways in which knowledge is constructed need to change in order to address sustainability issues. As Sarewitz (2004) notes there is a need for recognition that science "can legitimately support...a range of competing, value-based political positions" (2004, p. 386).

\subsubsection{Agonistic processes}

The main difference between SAM and other cost-benefit accounting technologies is the process of deliberation by which values are assigned to parameters. In particular, it draws on Mouffe $(2000,2005)$ in using an agonistic process where differences of viewpoint are actively surfaced and debated and where a consensus view may not arise as it would in a more orthodox deliberative process. While such a difference may seem relatively minor, it has a potentially radical element when considering forms of engagement relevant to the sustainability accounting project as has been discussed by Bebbington, Brown \& Frame (2007), Bebbington et al. (2007), and Brown (2007).

However, this and other differences between SAM and other assessment and decision-making tools such as triple bottom line (TBL) reporting and cost-benefit analysis (CBA) can lead to uncertain expectations of what is represented in a SAM assessment. For example, employment may be used as a social indicator whereas employment (direct and indirect) is often considered an economic benefit in CBA and other neoclassical economic analyses. However, in the SAM case studies, direct 
employment was considered as an economic benefit and indirect employment a social benefit (Bebbington, 2007; Bebbington \& McGregor, 2005). For the allocation of project costs, in SAM the costs of the project were considered as part of the economic benefit of money going into society. This contrasts with classical CBA, which more often differentiates the 'costs' of a given project (to an organization) from the benefits of the project. It is also the use of monetization in SAM, including the visual presentation of costs and benefits that give rise to the perception of SAM as a form of

CBA. However, SAM comes from the perspective that if economic rationalism dominates management decisions, then providing an alternative information set built around monetization provides a means to ensure consideration of sustainability issues (Bebbington, Brown, \& Frame, 2007). Further, SAM seeks to make explicit the subjectivity surrounding monetization as explored further by Bebbington, Brown, \& Frame (2007). The key element, however, is the extent to which the process of developing the accounts takes on an agonistic form.

\section{Concluding comments}

Undertaking the case studies has provided material for future improvements; distinguishing, perhaps, SAM more as a multicriteria-based decision-making tool than as a FCA tool as originally intended. As stated earlier, SAM's intent is to ensure sustainability issues are considered in arenas where economic rationalism dominates management decisions to make the subjectivity and assumptions associated with 
monetization explicit. However, gaps exist in the robustness of externality valuations leading to a tendency to play down the significance of resource usages and environmental impacts compared to that 'expected' from a 'green' perspective. Often when an assessment is presented there is a tendency to 'forget' these subjective elements and focus on the absolute figures, as noted by Smark (2006). Participation of the stakeholders is critical in order to create awareness of the subjectivity inherent in the monetization process. Further, stakeholders must recognize the value of the monetization process in establishing significant impacts and their influence on a project's sustainability.

Appropriate stakeholder participation will remain a challenging aspect of the SAM process as it requires a shift from a traditional researcher/contractor-client relationship to more participatory processes. Further, there is a need to clarify the process and purpose of SAM to participating stakeholders in order to achieve their active participation in developing alternative options to what may have originally been proposed. A key aspect in achieving this participation is recognition that the technical aspect of SAM is secondary to its role as presenting a debate into sensitivity of not only what the stakeholder believes to be important, but also the importance of societal externalities that may not have been considered and the need for open-mindedness about alternative options.

The extent to which these new forms of partnership were enabled in the various case studies was quite limited. The researcher-stakeholder relationship proceeded mostly, though not exclusively, along quasi consultant-client lines rather than develop new forms of partnership. Given the market-oriented approach to research relationships 
in New Zealand this is not too surprising and it underlines the complex environment in which new approaches must compete for credibility. Perhaps it is not possible for the participatory processes required for sustainability accounting to prosper in a market where the emphasis is on competition rather than cooperation for, as Marquand (2004, p. 33) notes, "the market domain consumes trust; it does not produce it" in what he refers to as the 'hollowing out of citizenship'. If this is the case, then an important precondition for new frameworks for accounting would seem to require significant changes in relationships such as the provider-client one. Indeed, as suggested by Marquand's thesis, significant changes are required in the development of the 'public', that is, the nature of what individuals and entities construct as citizenship.

To conclude, the adolescent metaphor retains its usefulness from the introduction and it enables us to provide guidance as we attempt to find ways to assess infrastructure projects for their contribution to (or from) an increased state of sustainability. Clearly, SAM is some way from a mature adulthood when it will be an independent agent. As researcher-caregivers, there is still some nurturing to be done before SAM (and others of its cohort) achieve a robust set of life skills and can deliver value to potential clients. It is also unlikely that it will ever be entirely free of its parental guidance - and perhaps that is not such a bad thing.

\section{Acknowledgements}


We thank the New Zealand Foundation for Research, Science and Technology for funding under the 'Building capacity for sustainable development: The enabling research' project (C09X0310). Contributions by the anonymous referees and Jonathan King have added significantly to the paper and are gratefully acknowledged. Earlier drafts were presented at the New Zealand Society for Sustainability Engineering and Science's 2nd International Conference on Sustainability Engineering and Science, 2123 Feb 2007, Auckland, New Zealand, and at the International Conference on Whole Life Urban Sustainability and its Assessment, 27-29 June 2007, Glasgow Caledonian University, Scotland. We are grateful to the various organizations involved for the opportunity to undertake SAMs and to work with them as they tackle sustainability issues.

\section{References}

Antheaume, N. (2007). Full cost accounting: Adam Smith meets Rachel Carson? In J. Unerman, J. Bebbington, \& B. O’Dwyer (Eds.) Sustainability accounting and accountability (pp. 211-225). Abingdon, UK: Routledge.

Arrow, K. J. (1963). Social choice and individual values (2nd ed.). New York: John Wiley. 
Astleithner, F., \& Hamedinger, A. (2003). The analysis of sustainability indicators as socially constructed policy instruments: benefits and challenges of 'interactive research'. Local Environment, 8, 627-640.

Bang, H. P. (2004). Culture governance: governing self-reflexive modernity. Public Administration, 82(1), 157-190.

Baxter, T., Bebbington, J., \& Cutteridge, D. (2004). Sustainability assessment model: modelling economic, resource, environmental and social flows of a project. In A. Henriques, \& J. Richardson (Eds.), The triple bottom line: does it all add up? (pp. 113-120). London: Earthscan.

Bebbington, J. (2007). Accounting for sustainable development performance. Oxford, UK: CIMA.

Bebbington, J., \& Frame, B. (2003). Moving from SD reporting to evaluation: the sustainability assessment model. Chartered Accounting Journal of New Zealand, 82(7), 11-13.

Bebbington, J., \& MacGregor, B. (2005). Modelling and accounting for sustainable development. London: RICS Foundation.

Bebbington, J., Brown, J., \& Frame, B. (2007). Accounting technologies and sustainability assessment models. Ecological Economics, 61, 224-236.

Bebbington, J., Gray, R., Hibbitt, C., \& Kirk, E. (2001). FCA: An agenda for action. ACCA Research Report No. 73. London: ACCA. 
Bebbington, J., Brown, J., Frame, B., \& Thomson, I. (2007). Theorizing engagement: the potential of a critical dialogic approach. Accounting, Auditing \& Accountability Journal, 20(3), 356-381.

Birkin, F. (2000). The art of accounting for science: a prerequisite for sustainable development? Critical Perspectives on Accounting, 11, 289-309.

Birkin, F., Edwards, P., \& Woodward, D. (2005). Accounting's contribution to a conscious cultural evolution: an end to sustainable development. Critical Perspectives on Accounting, 16, 185-208.

Booz, Allen and Hamilton. (2005). Surface transport costs and charges study. Environmental Impacts Working Paper. Report for the Ministry of Transport.

Boyce, G. (2000). Public discourse and decision making: exploring possibilities for financial, social and environmental accounting. Accounting, Auditing and Accountability Journal, 13(1), 27-64.

Brown, J. (2007). Democracy, sustainability and accounting technologies: the potential of dialogic accounting. Landcare Research Working Paper, available at: http://www.landcareresearch.co.nz/research/programme_pubs.asp?Proj_Collab_ID $=5$.

Cavanagh, J. E. (2005). Assessment of waste disposal vs resource recovery. Landcare Research Contract Report LC0506/022 for Environment Waikato. Available at: http://www.ew.govt.nz/publications/technicalreports/tr0535.htm. 
Cavanagh, J. E. (2007). Application of the sustainability assessment model: Assessment of the Acheson Ave redevelopment. Landcare Research Contract Report LC0607/115 for Housing New Zealand Corporation.

Cavanagh, J. E., Frame B., \& Lennox, J. A. (2006). The Sustainability Assessment Model (SAM): measuring sustainable development performance. Australasian Journal of Environmental Management, 13, 31-34.

Chapman, R., Goldberg, E., Salmon, G., \& Sinner, J. (2003). Sustainable development and infrastructure. Report for New Zealand Ministry of Economic Development. Available at: http://www.med.govt.nz/templates/MultipageDocumentTOC_9139.aspx.

Chapman, R., Howden-Chapman, P., \& O’Dea, D. (2004). A cost-benefit evaluation of housing insulation: results from the New Zealand 'Housing, Insulation and Health' study.

http://www.otago.ac.nz/wsmhs/academic/dph/research/housing/publications/Insulat ion\%20benefits\%2031 oct042.doc [accessed December 2006].

Chapman, R., Howden-Chapman, P., O’Dea, D., Viggers, H., \& Kennedy, M. (2006). Retrofitting houses with insulation: a cost-benefit analysis of a randomised community trial. http://www.maarama.co.nz/papers/Insulation_Benefits_feb07 [accessed February 2007].

Coase, R. (1960). The problem of social cost. Journal of Law and Economics, 3, 1-44. 
Dalal-Clayton, B., \& Sadler, B. (2005). Sustainability assessment: A review of international experience and practice. London: IIED.

Deegan C., \& Soltys, S. (2007). Social accounting research: An Australasian perspective. Accounting Forum, 31, 73-89.

Department of Prime Minister and Cabinet. (2003). Sustainable development for New Zealand: Programme of Action. Wellington, New Zealand: DPMC.

European Commission. (1995). ExternE: externalities of energy-methodology annexes. http://externe.jrc.es/.

European Commission. (2005). ExternE: externalities of energy—methodology 2005 update. http://www.externe.info/.

Frame, B. (in press). 'Wicked', 'messy' and 'clumsy': Long-term frameworks for sustainability. Environment and Planning C: Government and Policy.

Frame, B., \& Brown, J. (2008). Developing post-normal sustainability technologies. Ecological Economics, 65, 225-241

Frame, B., \& Marquardt, M. (2006). Implications of the Sustainable Development Programme of Action. Landcare Research Report LC0607/015. Available at: http://www.landcareresearch.co.nz/publications/researchpubs/LCR_SDPOA_revie w_2006.pdf 
Frame, B., \& O’Connor, M. (2008). In a wilderness of mirrors: Complexity, sustainability assessment and confounded meta-narratives. Landcare Research Working Paper, submitted to Science, Technology and Human Values.

Fraser, M. (2007). An attempt of organisational change with an experimental accounting technology. Presented at The Fifth Asia Pacific Interdisciplinary Research in Accounting (APIRA) Conference, Auckland, New Zealand. Available at: http://www.mngt.waikato.ac.nz/ConferenceManager/report.asp?issue=5.

Friedrich, R., \& Bickel, P. (2001). Environmental external costs of transport. Berlin, Heidelberg, New York: Springer-Verlag.

Funtowicz, S. (2006). Why knowledge assessment? In Â. Guimarães Pereira, S. Guedes Vaz, \& S. Tognetti (Eds.), Interfaces between sience and society (pp. 138-145). Sheffield: Greenleaf.

Funtowicz, S. O., \& Ravetz, J. R. (1993). Science for the post-normal age. Futures, 25, $739-755$.

Funtowicz, S. O., \& Ravetz, J. R. (1994). The worth of a songbird: ecological economics as a post-normal science. Ecological Economics, 10, 197-207.

Haag, D., \& Kaupenjohann, M. (2001). Parameters, prediction, post-normal science and the precautionary principle - a roadmap for modelling for decision-making. Ecological Modelling, 144, 45-60.

Herbohn, K. (2005). A full cost environmental accounting experiment. Accounting, Organizations and Society, 30(6), 519-536. 
Hohmeyer, O. (1988). Social costs of energy consumption. Berlin: Springer.

Howden-Chapman, P., Matheson, A., Crane, J., Viggers, H., Cunningham, M., Blakely, T., Cunningham, C., Woodward, A., Saville-Smith, K., O’Dea, D., Kennedy, M., Baker, M., Waipara, N., Chapman, R., \& Davie, G. (2007). Effect of insulating houses on health inequality: cluster randomised study in the community. British Medical Journal, DOI: 10.1136/bmj.39070.573032.80.

Hyde, L. (1983). The gift: imagination and the erotic life of property. New York: Vintage Books.

Kim, S. H. (2007). Evaluation of negative environmental impacts of electricity generation: Neoclassical and institutional approaches. Energy Policy, 35, 413-423.

Krewitt, W. (2002). External costs of energy — do the answers match the questions? Looking back at 10 years of ExternE. Energy Policy, 30(10), 839-848.

Lamberton, G. (2005). Sustainability accounting - a brief history and conceptual framework. Accounting Forum, 29, 7-26.

Land Transport New Zealand. (2005). Project evaluation manual-amendment 9 October 2005. Available at: http://www.ltsa.govt.nz/funding/manuals.html

Markandya, A., \& Tamborra, M. (Eds.) (2002). Green accounting in Europe: a comparative study. FEEM Series, Economics, Energy, Environment, 2. Edward Elgar. 
Marquand, D. (2004). Decline of the public: the hollowing out of citizenship. Cambridge, UK: Polity Press.

Mayumi, K., \& Giampietro, M. (2006). The epistemological challenge of selfmodifying systems: governance and sustainability in the post-normal science era. Ecological Economics, 57, 382-399.

Miller, C. A. (2005). New civic epistemologies of quantification: making sense of indicators of local and global sustainability. Science, Technology, \& Human Values, 30, 403-432.

Mouffe, C. (2000). The democratic paradox. London: Verso.

Mouffe, C. (2005). On the political. London: Routledge.

Ness, B., Urbel-Piirsalu, E., Anderberg, S., \& Olsson, L. (2007). Categorising tools for sustainability assessment. Ecological Economics, 60, 498-508.

O'Connor, M. (2000). Pathways for environmental valuation: a walk in the (hanging) gardens of Babylon. Ecological Economics, 34, 175-193.

O'Connor, M. (2006). The four "spheres" framework for sustainability. Ecological Complexity, 3(4), 285-292.

Pearce, D. W. (1978). The valuation of social cost. London: Allen \& Unwin.

Pigou, A. (1920). Economics of welfare. London: Macmillan.

Polanyi, K. (1944). The great transformation. Boston: Beacon. 
Pretty J. N., Brett, C., Gee, D., Hine, R. E., Mason, C. F., Morison, J. I. L., Raven, H., Rayment, M. D., \& van der Bijl, G. (2000). An assessment of the total external costs of UK agriculture. Agricultural Systems, 65, 113-136.

Ravetz, J. R. (1987). Usable knowledge, usable ignorance: incomplete science with policy implications. In W. C. Clark, \& R. E. Munn (Eds.), Sustainable development of the biosphere (pp. 415-432). Cambridge: Cambridge University Press.

Ravetz, J. R. (2006). Post-normal science and the complexity of transitions towards sustainability. Ecological Complexity, 3, 275-284.

Ravetz, J. [R], \& Funtowicz, S. (1999). Post-normal science - an insight now maturing. Futures, 31, 641-646.

Rayner, S. (2006). Wicked problems: clumsy solutions - diagnoses and prescriptions for environmental ills. Available at: www.martininstitute.ox.ac.uk/NR/rdonlyres/C3EDD045-9E3B-4053-92299CF76660AAC6/645/JackBealeLectureWickedproblems.pdf.

Rittel, H. W. J., \& Webber, M. M. (1973). Dilemmas in a general theory of planning. Policy Sciences, 4, 155-169.

Sagoff, M. (1988). The economy of the Earth. Cambridge: Cambridge University Press.

Sarewitz, D.,2004, How science makes environmental controversies worse. Environmental Science and Policy, 7, pp. 385-403. 
Sen, A. K. (1977). Rational fools: a critique of the behavioral foundations of economic theory. Philosophy \& Public Affairs, 6, 317-344.

Shapiro, M. (1988). Introduction: judicial selection and the design of clumsy institutions. Southern California Law Review, 61, 1555-1563.

Smark, C. (2006). Costing schizophrenia. Accounting Forum, 30, 341-358.

Söderholm, P., \& Sundqvist, T. (2003). Pricing environmental externalities in the power sector: ethical limits and implications for social choice. Ecological Economics, 46, $333-350$.

Stirling, A. (1997). Limits to the value of external costs. Energy Policy, 25(5), 517-540.

Unerman, J., Bebbington, J., \& O’Dwyer, B. (Eds.) (2007). Sustainability accounting and accountability. Abingdon, UK: Routledge.

van Asselt M. B. A., \& Rijkens-Klomp, N. (2002). A look in the mirror: reflection on participation in integrated assessment from a methodological perspective. Global Environmental Change, 12, 167-184.

Verweij, M., \& Thompson, M. (2006). Clumsy solutions for a complex world: governance, politics and plural perceptions. Basingstoke/New York: Palgrave Macmillan.

Verweij, M., Douglas, M., Ellis, R., Engel, C., Hendriks, F., Lohmann, S., Ney, S., Rayner S., \& Thompson, M. (2006). Clumsy solutions for a complex world: the case of climate change. Public Administration, 84(4), 817-843. 
Watkiss, P. (2002). Fuel taxation inquiry: The air pollution costs of transport in Australia. A report for the Commonwealth of Australia. AEA Technology Environment, UK.

Weaver, P. M., \& Rotmans, J. (2006). Integrated sustainability assessment: what is it, why do it and how? International Journal of Innovation and Sustainable Development, 1, 284-303.

White, P. A., Sharp, B. M. H., \& Reeves, R. R. (2004). New Zealand water bodies of national importance for domestic use and industrial use. Report prepared for the New Zealand Ministry of Economic Development.

http://www.med.govt.nz/templates/MultipageDocumentPage_12531.aspx\#P1393_3 5618 [accessed December 2006]. 
Figure Caption

Fig. 1. Components of a sustainability accounting framework (from Lamberton, 2005).

Fig. 1

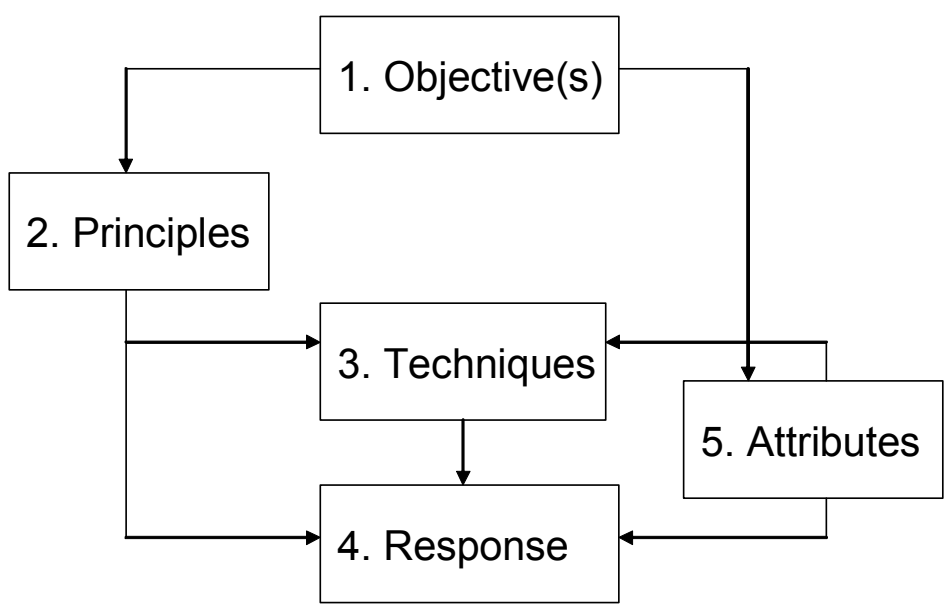




\section{Table 1}

Steps in Full-cost Accounting (FCA)

1 Define the focus of the costing exercise. This may be, for example, a product, production process, waste disposal option, project, part of an economic entity, an entire entity, or an entire industry - and is the overall cost objective.

2 Specify the scope or limits of analysis. This is the subset of all possible externalities to be identified.

Identify and measure external impacts. This involves making the link between a cost objective and the externalities arising from the cost objective.

Cost external impact. This is the monetization of the externalities, or determination of the fuller costs associated with, but which are not already captured by, the current accounting for the cost objective.

Source: Bebbington \& MacGregor (2005). 